\title{
Clinical outcomes and survival analysis for petroclival meningioma patients receiving surgical resection: an analysis of 176 cases
}

This article was published in the following Dove Press journal: Cancer Management and Research

\author{
Li Qiaol,2 \\ Chunjiang $\mathrm{Yu}^{\prime}$ \\ Hongwei Zhang' \\ Mingshan Zhang' \\ Yanming Qu' \\ Ming Ren' \\ Chunyu Gu' \\ Haoran Wang' \\ 'Department of Neurosurgery, Sanbo \\ Brain Hospital, Capital Medical \\ University, Beijing, People's Republic of \\ China; ${ }^{2}$ Department of Neurosurgery, \\ Gansu Provincial Hospital, Lanzhou, \\ Gansu Province, People's Republic of \\ China
}

Purpose: The relationship of clinical results and survival analysis of operative patients with petroclival meningioma (PCM) was studied.

Patients and methods: Data from a total of 176 PCM patients receiving surgical resection were retrospectively collected. Follow-up was conducted through outpatient review by reexamination telephone calls and letters. Clinical outcomes, survival, and Karnofsky Performance Scale (KPS) data were analyzed.

Results: Seventy-two percent of patients (127/176) received only surgery, 8.5\% (15/176) received surgery and adjuvant radiation therapy (RT) (surgery + RT), and 19.3\% (34/176) received surgery and adjuvant gamma knife surgery (GKS) (surgery + GKS). Gross total resection (GTR) was performed in $34.7 \%$ of patients $(61 / 176)$, subtotal resection (STR) in $58.0 \%$ (102/176), and partial resection (PR) in 7.4\% (13/176). Recent follow-up KPS was higher than preoperative ( 80 vs $70, P<0.05$ ) and postoperative KPS ( 80 vs $70, P<0.05$ ). Cumulative survival was the same for $3,5,7$, and 9 years, ie, 95\%, and mean survival time (MST) was (110.83 \pm 2.55$)$ months (95\% CI: 105.83-115.83). Recurrence/progression (R/P)-free survival was $88.9 \%, 86.9 \%, 71.1 \%$ and $71.1 \%$, respectively for $3,5,7$, and 9 years, and MST was $(100.58$ \pm 3.82 ) months (95\% CI: 93.11-108.06). R/P (HR: 5.486, 95\% CI: 1.655-18.180), surgery + RT (HR: 0.125, 95\% CI: 0.016-0.990) and WHO grade III (HR: 2.766, 95\% CI: 1.146-6.676) were independently associated with cumulative survival. Lack of adhesion to and encasement of neurovascular structures was independently associated with R/P-free survival (HR: 2.002, 95\% CI: 1.023-3.919).

Conclusion: Surgical treatment was safe and effective for PCM. R/P, surgery + RT, and WHO grade III were independently associated with cumulative survival. Lack of adhesion to and encasement of neurovascular structures was independently associated with R/P-free survival. These factors should be paid attention to in surgical treatment of PCM.

Keywords: petroclival meningiomas, resection, survival, radiation, therapy gamma knife surgery

\section{Introduction}

Petroclival meningiomas (PCMs) account for about $2 \%$ of posterior fossa meningiomas. ${ }^{1-4}$ As lesions arising from the petroclival junction at the upper two thirds of the clivus, PCMs are located medial to the trigeminal nerve. ${ }^{4,5}$ Resection of PCMs had high mortality and morbidity in the past, because of the vital structures adjacent to the origin of PCMs and the difficulty in approaching the petroclival region. ${ }^{6-10}$ However, clinical outcomes of resection of PCMs have been considerably
Correspondence: Chunjiang Yu Department of Neurosurgery, Sanbo Brain Hospital, Capital Medical University Xiangshan Yikesong 50, Haidian District, Beijing 100093, People's Republic of China Tel +860106 2856719

Fax +8601062856719

Email yuchunjiangsurgeon@I26.com 
improved following advances in neuroimaging and introduction of refined skull base techniques. ${ }^{11-13}$ In this paper, the clinical outcomes of 176 PCM patients receiving surgical resection were reported and the survival analysis was conducted. The aim was to provide clues for improving the prognosis of PCM patients receiving surgical resection.

\section{Materials and methods}

\section{Patients}

A total of 176 PCM patients receiving surgical resection in Sanbo Brain Hospital between May 2006 and October 2015 were retrospectively collected. They included 52 males and 124 females with an average age of $(48.8 \pm 12.1)$ years. Followup was completed in 163 patients (follow-up rate: 92.6\%), and they included 48 males and 115 females with an average age of $(48.3 \pm 12.4)$ years. Both gender and age were not statistically different between the total patients and the follow-up patients (both $P<0.05$ ). The flow diagram of patients for this study was shown in Figure 1. This study was approved by the ethics committee of Beijing Sanbo Brain Hospital. All follow-up patients provided written informed consent, and this study was conducted in accordance with the Declaration of Helsinki.

\section{Imaging evaluation}

Computed tomography (CT) and magnetic resonance imaging (MRI) were performed in all patients. Tumor equivalent diameter (TED) was calculated with the formula “( $(\mathrm{D} 1 \times \mathrm{D} 2 \times \mathrm{D} 3)^{1 / 3}$ ". PCM was classified as small $(<1.0 \mathrm{~cm})$, medium $(1.0-2.4 \mathrm{~cm})$, large $(2.5-4.4 \mathrm{~cm})$ and giant $(\geq 4.5 \mathrm{~cm})$ according to TED. ${ }^{5}$ Imaging evaluation also included skull base bone erosion/osteoproliferation, tumor vascularity, peritumoral edema and so on.

\section{Surgical resection}

Gross total resection (GTR) was performed for PCMs with Simpson grade I/II, subtotal resection (STR) for Simpson Grade III/IV and partial resection (PR) for Simpson grade IV. Adjuvant radiation therapy (RT) or gamma knife surgery (GKS) was performed for PCM patients with Simpson grade III/IV and WHO grade II/III according to World Health Organization 2016 Classification of Central Nervous System Tumors. ${ }^{14}$ Adjuvant RT or GKS was not performed for WHO grade I patients undergoing GTR. WHO II/III patients undergoing STR, PR, or GTR received adjuvant radiotherapy (RT) or GKS within 3 months after surgery. The surgical approaches included subtemporal transtentorial petrosalapex, retrosigmoid, presigmoid, subtemporal transtentorial petrosalapex combined with retrosigmoid, far-lateral transcondylar, frontotemporal/ orbitozygomatic osteotomy, frontotemporal combined with subtemporal transtentorial petrosalapex, and retrosigmoid combined with far-lateral transcondylar.

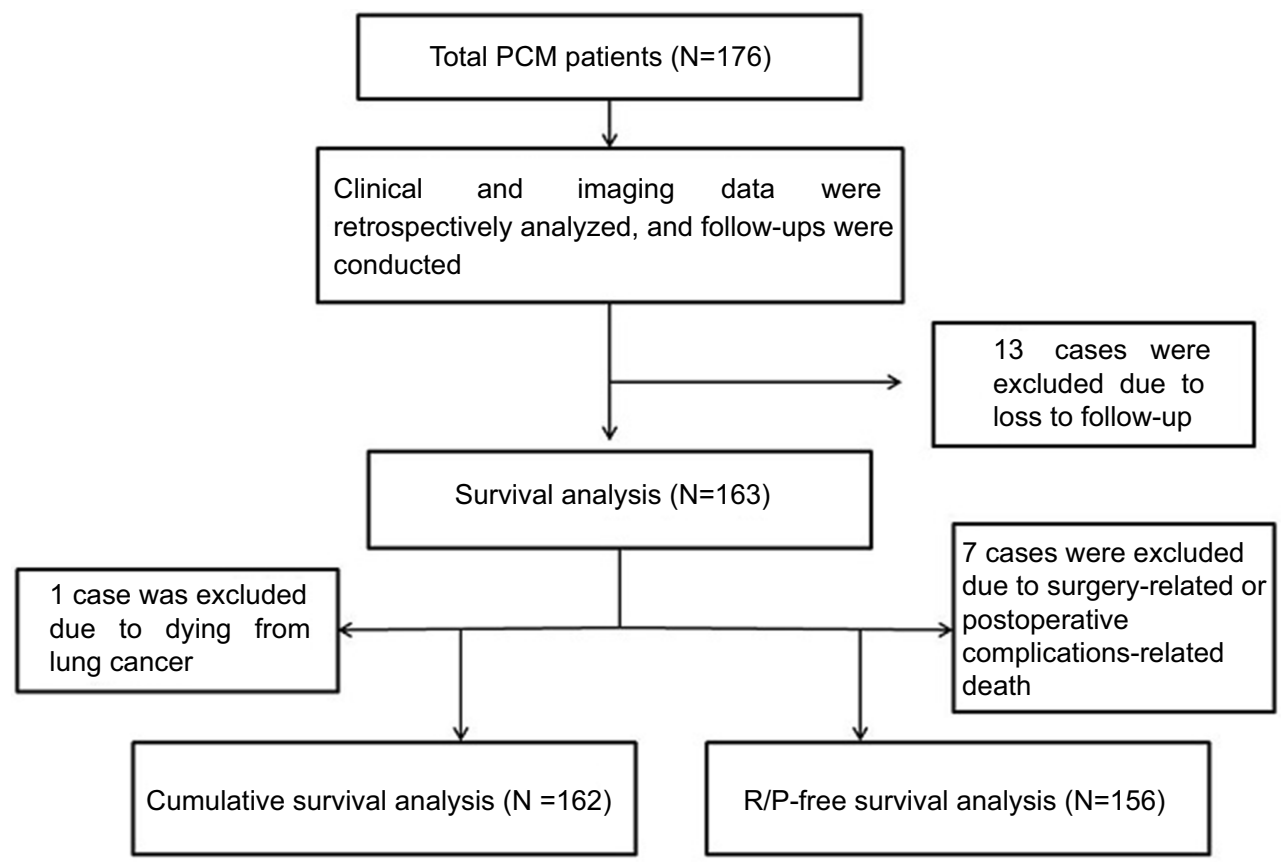

Figure I Flow diagram of patients for this study.

Abbreviations: PCM, petroclival meningioma; R/P, recurrence/progression. 
Ten surgeons were involved in the execution of the surgical removal of the petroclival meningiomas. All of them are experienced with such approaches. Chunjiang $\mathrm{Yu}$, the corresponding author, is one of the leading experts of skull base surgery and established the first laboratory for microsurgery of the skull base in China. He has been engaged in neurosurgery for nearly 30 years and performed more than 10,000 cases of various intracranial tumor surgeries. Chunjiang $\mathrm{Yu}$ and his team have rich experience in skull base anatomy and surgical techniques to ensure good postoperative outcomes.

\section{Follow-up method}

Follow-up was conducted through outpatient review, telephones and letters. Survival data and Karnofsky Performance Scale (KPS) data at 1 month after surgery (postoperative KPS) and in July 2016 (recent follow-up KPS) were collected. 13 patients were lost follow-up because of changed postal addresses and telephone numbers.

\section{Statistical analysis}

The SPSS version 20.0 for Windows (IBM Corporation, Armonk, NY, USA) was used to perform statistical analysis, and significance was set at $P<0.05$. Quantitative data were tested for normality with Kolmogorov-Smirnov test, and normal data were expressed as mean $\pm \mathrm{SD}$ and abnormal data were expressed as median IQR. Qualitative data were expressed as percentages or ratios. Univariate survival analysis was performed using Kaplan-Meier analysis, and multivariate survival analysis was performed using Cox regression model. The factors with $P<0.1$ in univariate survival analysis were included in Cox regression model. Nonparametric test employed Mann-Whitney $\mathrm{U}$ test.

\section{Results}

\section{Clinical characteristics}

Among the total patients, $97.7 \%$ of patients (172/176) had the typical symptoms and signs of PCMs preoperatively, and $2.3 \%$ of patients $(4 / 176)$ were asymptomatic whose lesions were discovered by accident by imaging examination. The duration of symptom onset at admission ranged from 1 to 240 months with a median of 12 months. The length of stay ranged from 9 to 281 days with a median of 24 days. Medium, large and giant PCMs accounted for $11.4 \%$ (20/ 176), $63.6 \%$ (112/176) and $25.0 \%$ (44/176), respectively, and none were small. Preoperative MRI/CT combined with intraoperative observation demonstrated that 16.5\% (29/ 176) of patients had peritumoral edema. $88.6 \%$ of patients (156/176) belonged to WHO grade I, 10.2\% (18/176) belonged to WHO grade II, and $1.1 \%(2 / 176)$ belonged to WHO grade III.

\section{Treatment modalities}

All patients received surgical resection. $72.2 \%$ of patients (127/176) received only surgery, $8.5 \%(15 / 176)$ received surgery and adjuvant RT (surgery + RT), and 19.3\% (34/ 176) received surgery and adjuvant GKS (surgery + GKS). GTR was performed in $34.7 \%$ of patients (61/176), STR in $58.0 \%(102 / 176)$ and PR in 7.4\% (13/176). Operative time ranged from 200 to 1070 minutes with a median of 390 minutes. Intraoperative bleeding ranged from 100 to $4000 \mathrm{~mL}$ with a median of $825 \mathrm{~mL}$. Surgical approaches were chosen according to the origin of the tumor base, size of the lesion, involved scope of the skull base and preoperative imaging evaluation (CT/MRI). Subtemporal transtentorial petrosalapex accounted for $36.9 \%(65 / 176)$, retrosigmoid accounted for $29.0 \%$ (51/176), presigmoid accounted for $15.9 \%$ (28/176), subtemporal transtentorial petrosalapex combined with retrosigmoid accounted for 9.7\% (17/176), far-lateral transcondylar accounted for $6.3 \%$ (11/176), frontotemporal/orbitozygomatic osteotomy accounted for $4.0 \%$ (7/176), frontotemporal combined with subtemporal transtentorial petrosalapex accounted for $2.3 \%(4 / 176)$, and retrosigmoid combined with farlateral transcondylar accounted for $0.6 \%(1 / 176)$.

\section{Complications and neurological dysfunction}

Major preoperative and postoperative symptoms and neurological dysfunctions were demonstrated in Table 1, and major preoperative and postoperative complications were demonstrated in Table 2. According to Table 1, early postoperative new neurological dysfunctions mainly included cranial nerve (CN) III (41.8\%), CN VI (26.1\%) and CN VII $(30.7 \%)$. According to Table 2, early postoperative new complications mainly included subdural or subcutaneous (SD/SC) hydrops (29.9\%), pneumonia (18.5\%) and intracranial infection (ICI) (16.1\%).

\section{Survival analysis}

The follow-up was up to July 2016. A total of 13 patients died, including 4 cases of surgery-related death, 3 cases of postoperative complications-related death, 1 case of lung 
Table I Major preoperative and postoperative symptoms and neurological dysfunction

\begin{tabular}{|c|c|c|c|c|c|}
\hline \multirow[t]{2}{*}{ Symptoms } & \multirow[t]{2}{*}{ Preoperative $^{\mathrm{a}}(\%)$} & \multicolumn{3}{|c|}{ Postoperative $^{b}$ (\%) (I month) } & \multirow{2}{*}{$\begin{array}{l}\text { Recent }^{c} \\
(\%)\end{array}$} \\
\hline & & Improved (\%) & Worsened (\%) & New onset (\%) & \\
\hline Dizziness & $49 / 176(27.8)$ & $34 / 49(69.4)$ & 2/49(4.1) & $4 / 127(3.1)$ & $1 / 163(0.6)$ \\
\hline Epilepsy & $7 / 176(4.0)$ & $2 / 7(28.6)$ & $\mathrm{I} / 7(\mid 4.3)$ & $6 / 169(3.6)$ & $1 / 163(0.6)$ \\
\hline Ataxia & $46 / 176(26.1)$ & $5 / 46(3.1)$ & 0 & $6 / 130(4.6)$ & $36 / 163(22.1)$ \\
\hline $\mathrm{M} / \mathrm{H}$ & $27 / 176(15.3)$ & $\mathrm{II} / 27(40.7)$ & $7 / 27(25.9)$ & $33 / 149(22.1)$ & $40 / 163(24.5)$ \\
\hline $\mathrm{CN}$ II & $30 / 176(17.0)$ & $4 / 30(13.3)$ & $1 / 30(3.3)$ & $7 / 146(4.8)$ & $36 / 163(22.1)$ \\
\hline III & $35 / 176(19.9)$ & $3 / 35(8.6)$ & $21 / 35(60.0)$ & $59 / 14 \mid(4 \mid .8)$ & $75 / 163(46.0)$ \\
\hline IV & $22 / 176(12.5)$ & 0 & $\mathrm{I} / 22(4.5)$ & $24 / 154(15.6)$ & $39 / 163(23.9)$ \\
\hline V & $94 / 176(53.4)$ & $22 / 94(23.4)$ & $4 / 94(4.3)$ & $19 / 82(23.2)$ & $106 / 163(65.0)$ \\
\hline VI & $1 \mathrm{I} / 176(6.3)$ & I/II(9.I) & 0 & $43 / 165(26.1)$ & $40 / 163(24.5)$ \\
\hline VII & $36 / 176(20.5)$ & $3 / 36(8.3)$ & $15 / 36(4 \mid .7)$ & $43 / 140(30.7)$ & $61 / 163(37.4)$ \\
\hline VIII & $83 / 176(47.2)$ & $16 / 83(19.3)$ & $3 / 83(3.6)$ & $5 / 93(5.4)$ & 78/163(47.9) \\
\hline$I X / X$ & $66 / 176(37.5)$ & $21 / 66(31.8)$ & $20 / 66(30.3)$ & $25 / 110(22.7)$ & $57 / 163(35.0)$ \\
\hline XII & $16 / 176(9.1)$ & $1 / 16(6.3)$ & 0 & $13 / 160(8.1)$ & $30 / 163(18.4)$ \\
\hline Dysarthria & $7 / 176(4.0)$ & $2 / 7(28.6)$ & 0 & $23 / 169(13.6)$ & 19/163(11.7) \\
\hline Gait & $48 / 176(27.3)$ & $19 / 48(39.6)$ & $3 / 48(6.3)$ & $3 / 128(2.3)$ & $34 / 163(20.9)$ \\
\hline
\end{tabular}

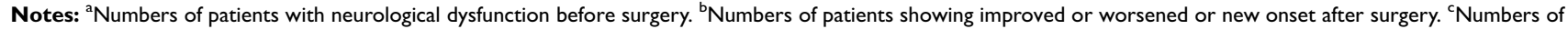
patients having neurological dysfunction at follow-up.

Abbreviations: $\mathrm{M} / \mathrm{H}$, monoplegia or hemiplegia; $\mathrm{CN}$, cranial nerve.

Table 2 Major preoperative and postoperative complications

\begin{tabular}{|c|c|c|c|c|c|}
\hline \multirow[t]{2}{*}{ Complications } & \multirow[t]{2}{*}{ Preoperative $^{\text {a }}(\%)$} & \multicolumn{3}{|c|}{ Postoperative $^{\mathrm{b}}$ (\%) (I month) } & \multirow{2}{*}{$\begin{array}{l}\text { Recent }^{c} \\
(\%)\end{array}$} \\
\hline & & Improved (\%) & Worsened (\%) & New onset (\%) & \\
\hline Hydrocephalus & $64 / 176(36.4)$ & 28/64(43.8) & $8 / 64(12.5)$ & $6 / 112(5.4)$ & 0 \\
\hline $\mathrm{ICl}$ & $2 / 176(I .1)$ & $2 / 2(100)$ & 0 & $28 / 174(16.1)$ & $1 / 163(0.6)$ \\
\hline $\mathrm{TH}$ & $15 / 176(8.5)$ & 0 & $1 / 15(6.7)$ & 0 & $14 / 163(8.6)$ \\
\hline $\mathrm{C} / \mathrm{K} / \mathrm{CU}$ & $3 / 176(1.7)$ & $2 / 3(66.7)$ & $\mathrm{I} / 3(33.3)$ & $\mathrm{II} / \mathrm{I73(6.4)}$ & $9 / 163(5.5)$ \\
\hline $\mathrm{ICH}$ & $1 / 176(0.6)$ & $\mathrm{I} / \mathrm{I}(100)$ & 0 & $24 / 175(13.7)$ & 0 \\
\hline Gastric ulcer & $\mathrm{I} / \mathrm{I76}(0.6)$ & $\mathrm{I} / \mathrm{I}(\mathrm{I00})$ & 0 & $1 \mathrm{I} / \mathrm{I75}(6.3)$ & 0 \\
\hline CFL & 0 & 0 & 0 & $7 / 176(4.0)$ & 0 \\
\hline DVT of extremity & $\mathrm{I} / \mathrm{I} 76(0.6)$ & 0 & $\mathrm{I} / \mathrm{I}(\mathrm{I00})$ & $2 / 175(I . I)$ & $2 / 163(1.2)$ \\
\hline Pneumonia & $8 / 176(4.5)$ & $4 / 8(50)$ & $2 / 8(25)$ & $31 / 168(\mid 8.5)$ & $2 / 163(1.2)$ \\
\hline SD/SC hydrops & $2 / 176(1.2)$ & $\mathrm{I} / 2(50)$ & $\mathrm{I} / 2(50)$ & $52 / 174(29.9)$ & 0 \\
\hline
\end{tabular}

Notes: ${ }^{a}$ Numbers of patients with symptoms/complications before surgery. ${ }^{b}$ Numbers of patients showing improved or worsened or new onset after surgery. ${ }^{\mathrm{c}}$ Numbers of patients still with symptoms/complications at follow-up.

Abbreviations: ICl, intracranial infection; $\mathrm{TH}$, tonsillar herniation; ICH, intracranial hematoma; $\mathrm{C} / \mathrm{K} / \mathrm{CU}$, conjunctivitis or keratitis or corneal ulcer; $\mathrm{CFL}$, cerebrospinal fluid leak; DVT, deep venous thrombosis, SD/SC, subdural or subcutaneous.

cancer-related death, and 5 cases of R/P-related death. For surgery-related deaths, 2 patients died from brain stem edema, 1 from infarction of the brain stem and thalamus, and 1 patient died from diffuse brain swelling. Postoperative complication-related deaths were mainly caused by respiratory failure associated with pulmonary infection. As shown in Figure 2, cumulative survival was the same for 3, 5, 7, and 9 years, ie, 95\%, and mean survival time was $(110.83 \pm 2.55)$ months $(95 \% \mathrm{CI}$ : 105.83-115.83).

\section{Cumulative survival analysis}

Kaplan-Meier analysis showed that R/P, existence of arachnoid membrane plane between neurovascular structures and tumor and WHO grading were significantly associated with cumulative survival (Figures 3, 4 and 5). Cox regression analysis showed that R/P (HR: 5.486, 95\%CI: 1.655-18.180), surgery + RT (HR: $0.125,95 \%$ CI: $0.016-0.990)$ and WHO grade III (HR: $2.766,95 \%$ CI: 1.146-6.676) were independently associated with cumulative survival. 


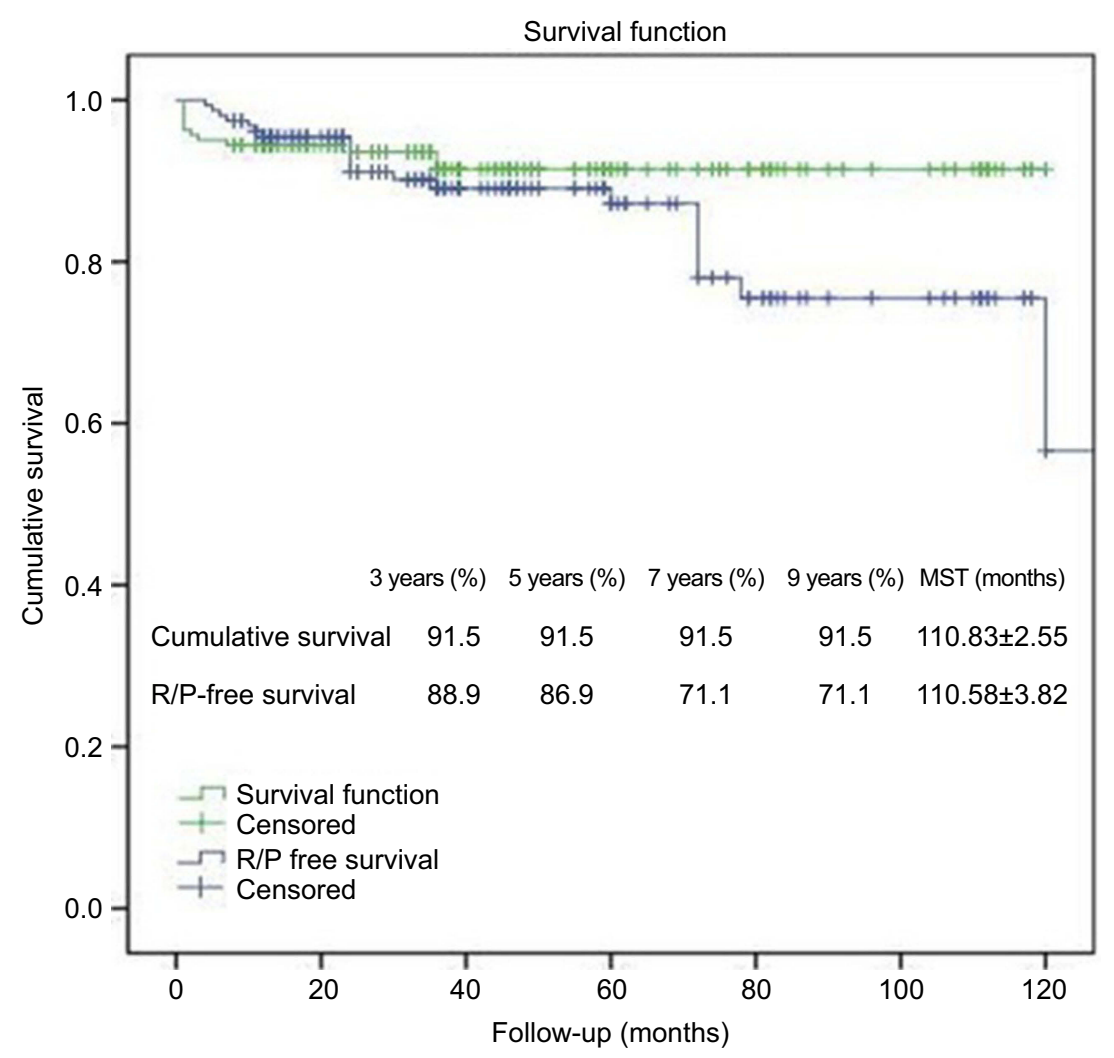

Figure 2 Cumulative survival and R/P-free survival of PCM patients receiving surgical resection.

Abbreviations: PCM, petroclival meningioma; R/P, recurrence/progression, MST, mean survival time.

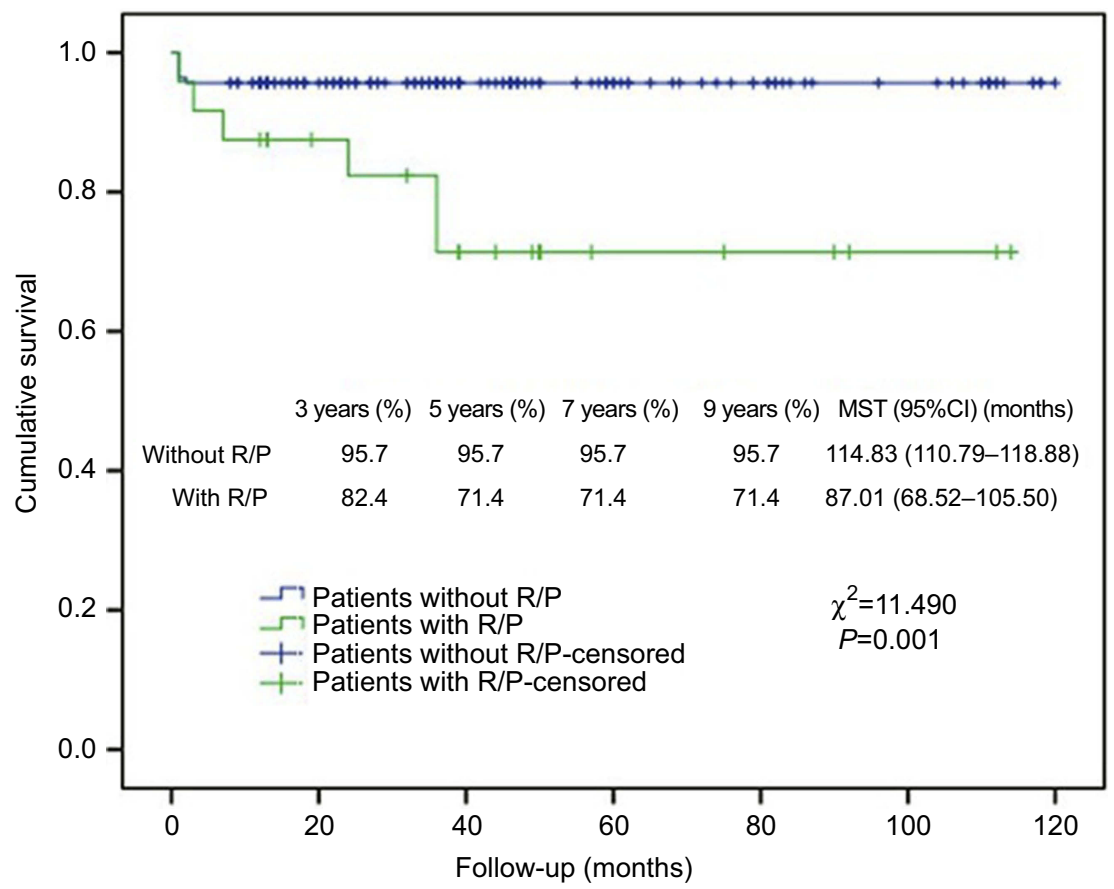

Figure 3 Kaplan-Meier analysis of cumulative survival for R/P using log rank test.

Abbreviations: R/P, recurrence/progression; MST, mean survival time. 


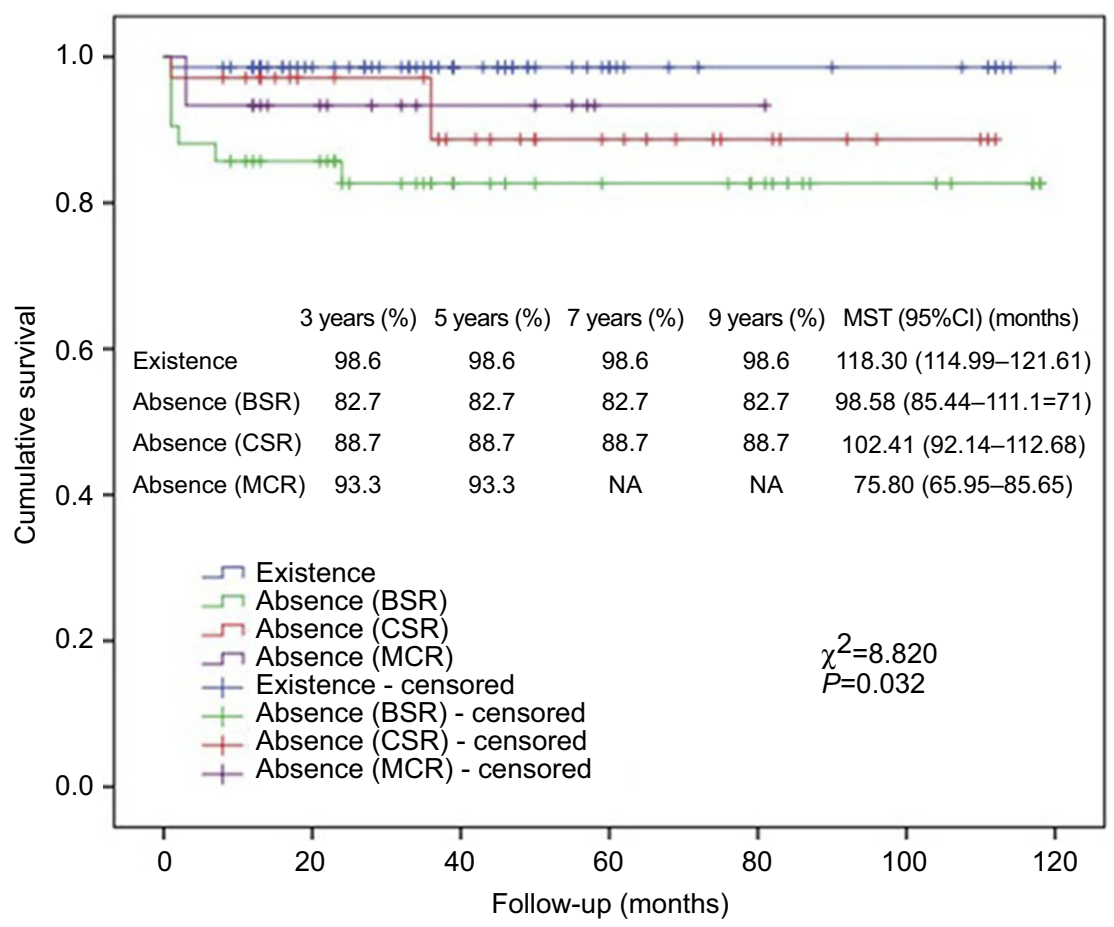

Figure 4 Kaplan-Meier analysis of cumulative survival for existence of arachnoid membrane plane between neurovascular structures and tumor using log rank test. Abbreviations: MST, mean survival time; BSR, brain stem region; CSR, cavernous sinus region; MCR, Meckel's cave region.

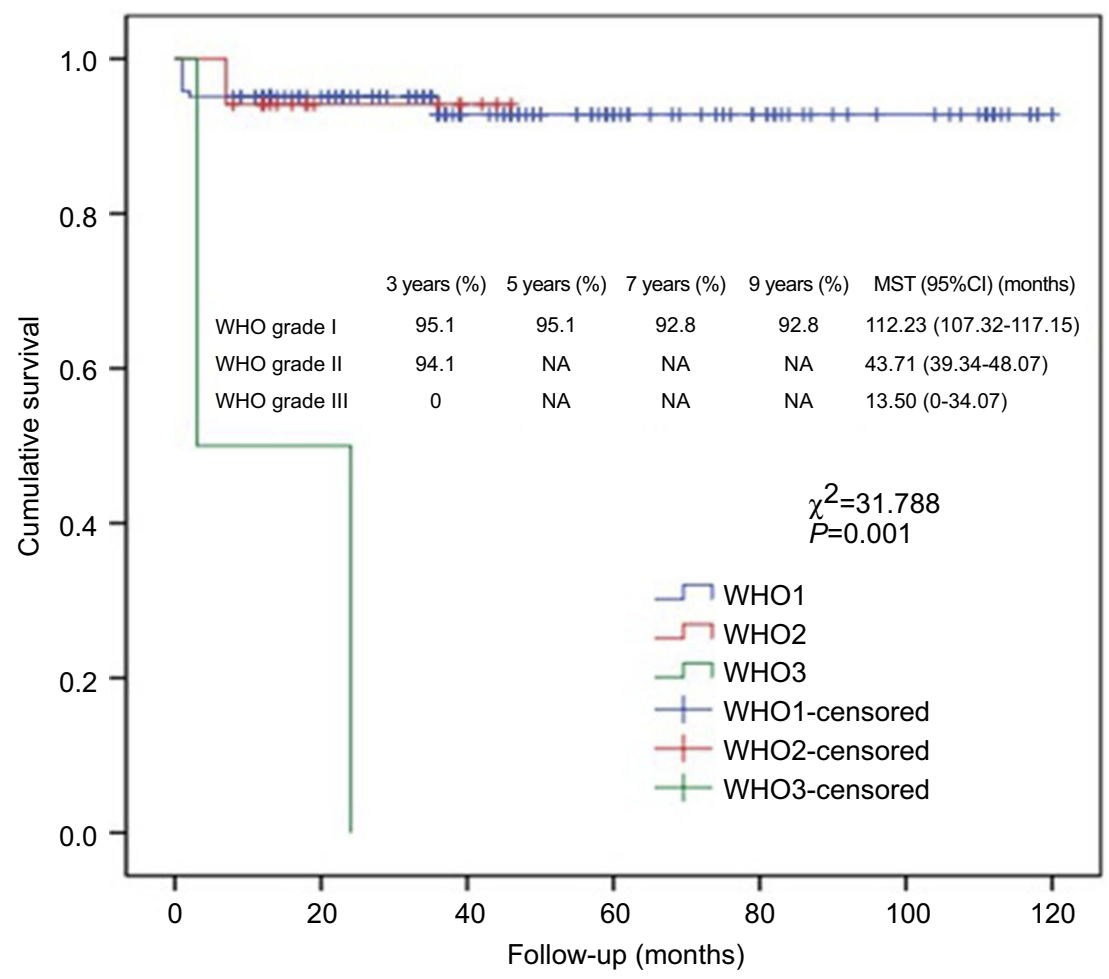

Figure 5 Kaplan-Meier analysis of cumulative survival for WHO grading using log-rank test.

Abbreviation: MST, mean survival time. 


\section{Recurrence and progression}

Tumor recurrence was defined as any newly identified lesion after GTR, and tumor progression was defined as increased residual tumor volume after STR or PR. $6.9 \%$ of GTR patients had recurrence (4/58), 16.5\% of STR patients had progression (15/91), and $15.4 \%$ of PR patients had progression (2/13). As shown in Figure 3, mean survival time (MST) was significantly longer in patients without $\mathrm{R} / \mathrm{P}$ than in patients with R/P. As shown in Figure 2, R/P-free MST of all patients was $(100.58 \pm 3.82)$ months $(95 \% \mathrm{CI}$ : 93.11-108.06), and R/P-free survival was $88.9 \%, 86.9 \%$, $71.1 \%$ and $71.1 \%$, respectively for $3,5,7$, and 9 years.

\section{R/P-free survival analysis}

Kaplan-Meier analysis showed that WHO grading and surgery or surgery + GKS were significantly associated with R/P-free survival (Figures 6 and 7), and GTR was almost statistically significant (Figure 8). Cox regression analysis showed that lack of adhesion to and encasement of neurovascular structures was independently associated with R/P-free survival (HR: 2.002, 95\%CI: 1.023-3.919).

\section{Karnofsky performance scale}

Recent follow-up KPS was 80 (20), preoperative KPS was 70 (20), and postoperative KPS was 70 (30). Recent follow-up KPS was higher than preoperative and postoperative KPS (both $P<0.05$, Figure 9).

\section{Discussion}

Originally most PCMs were considered unresectable. ${ }^{7}$ Resection of PCMs had a mortality of 50\% and a very high incidence of postoperative complications until the 1970s. ${ }^{15}$ Mayberg and Symon published the first report truly focusing on PCMs with relatively good results. ${ }^{16}$ The mortality for this series of patients was decreased to $9 \%$. Moreover, they had a markedly better long-term functional status compared with previous reports, although new or worsened cranial nerve deficits usually occurred after resection.

Since the 1980s, neuromonitoring and improved neuroanesthesia have been applied in approaching the skull base lesions in the petroclival region. Brain MRI was employed to evaluate these lesions preoperatively, and the feasibility of RT applied to STR lesions was also discussed.

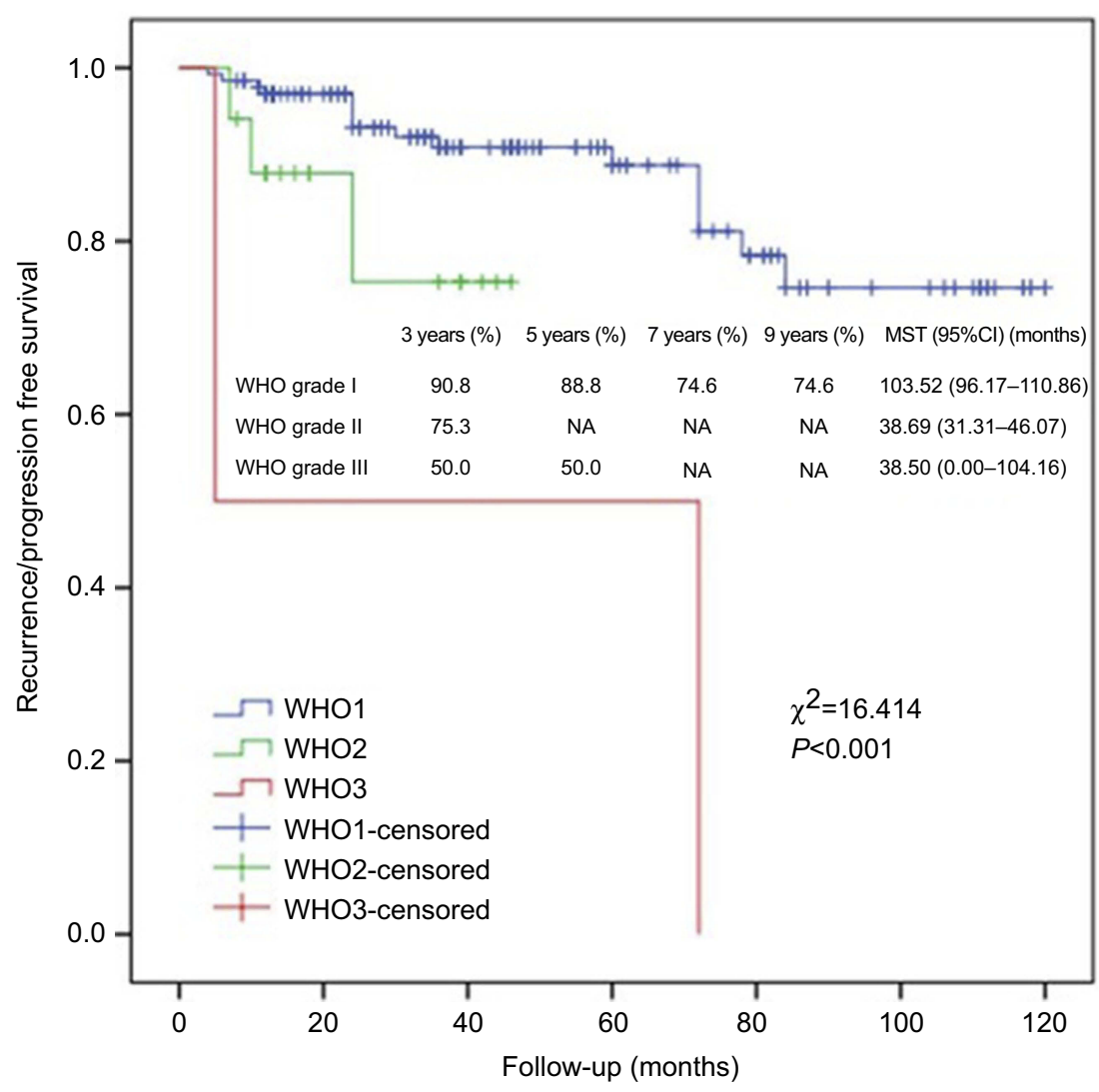

Figure 6 Kaplan-Meier analysis of R/P-free survival for WHO grading using log rank test. Abbreviation: MST, mean survival time; R/P, recurrence/progression. 


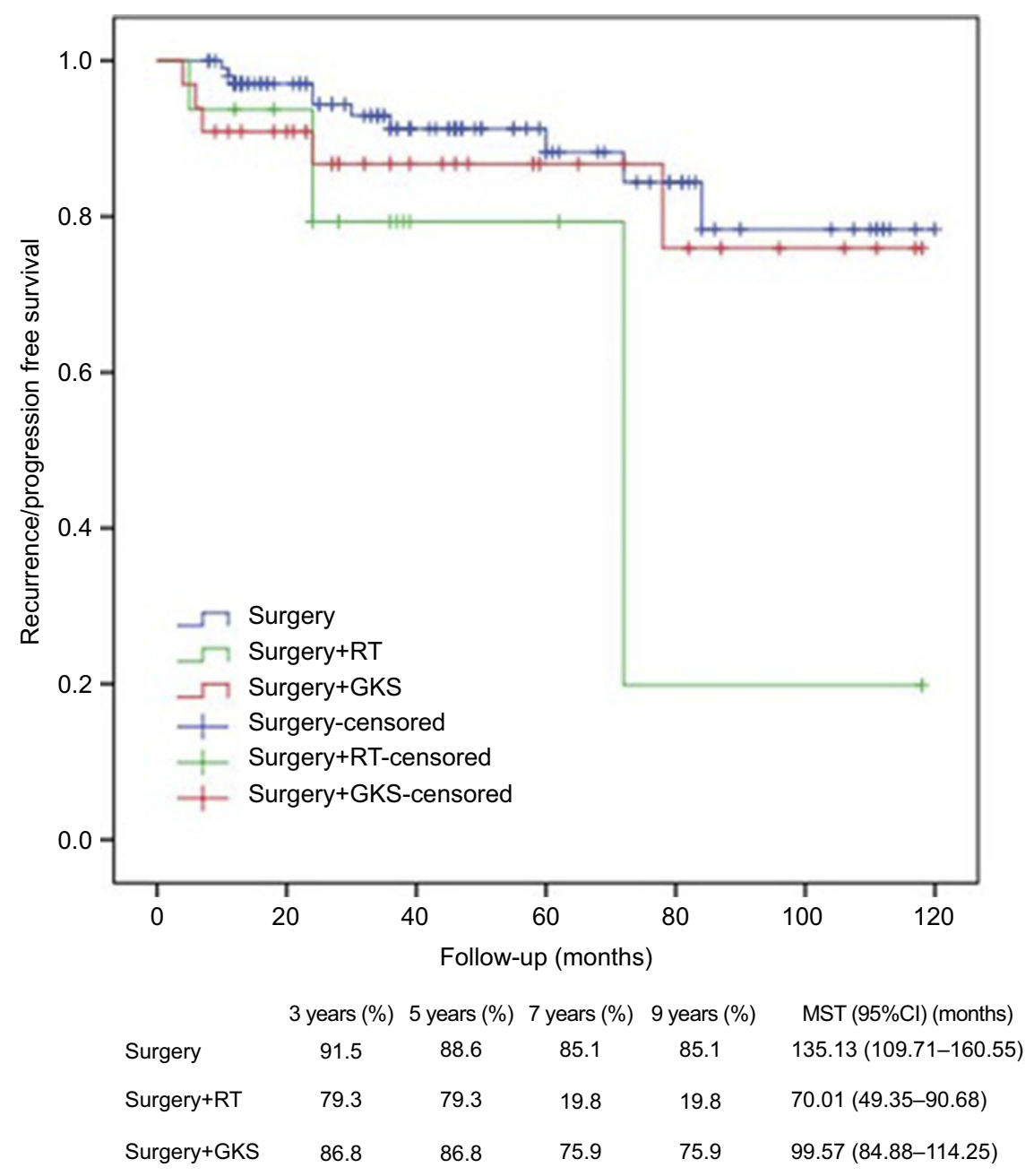

Figure 7 Kaplan-Meier analysis of R/P-free survival for treatment modalities using log rank test.

Abbreviations: MST, mean survival time; RT, radiation therapy; GKS, gamma knife surgery; R/P, recurrence/progression.

In 1996, Sekhar et al visited this topic and emphasized the importance of MRI in describing these lesions. ${ }^{17}$ Especially they indicated that the tumors would lose the subarachnoid plane necessary for dissection and derive blood supply from the vertebrobasilar system when the pia was invaded. Therefore, the risk of major complications was much higher if GTR was performed. Thus they concluded that the lesions with pial invasion should be managed with STR which left a thin rim of tumor on the brain stem with an aim of avoiding permanent neurologic damage. In addition, they demonstrated that early postoperative neurologic symptoms usually worsened after resection of these tumors $(60 \%$ of their patients), which was significantly associated with tumor size at the time of resection. However, the neurologic outcomes of these patients showed significant improvement with time, with only $16 \%$ among them having residual neurologic deficits.
The outcomes of irradiation applied to meningiomas were rather disappointing before the 1970s. Thus RT was thought valueless in managing meningiomas. ${ }^{18}$ However, several reports began to indicate that RT could be beneficial for patients with incompletely resected meningiomas. ${ }^{19-21}$ These studies demonstrated that postoperative RT could significantly reduce the incidence of local recurrence. The advent of radiosurgical therapy showed further promise for treating PCMs, especially after STR. Barbaro et al discussed the role of RT in subtotally resected meningiomas in all locations in 1987. ${ }^{22}$ The patients were divided into three groups according to treatment modalities: GTR, STR without adjuvant RT and STR with RT. The recurrence rates were $4 \%, 60 \%$ and $32 \%$, respectively for GTR, STR without RT and STR with RT. In addition, the time to recurrence was significantly longer in patients receiving STR with RT than 


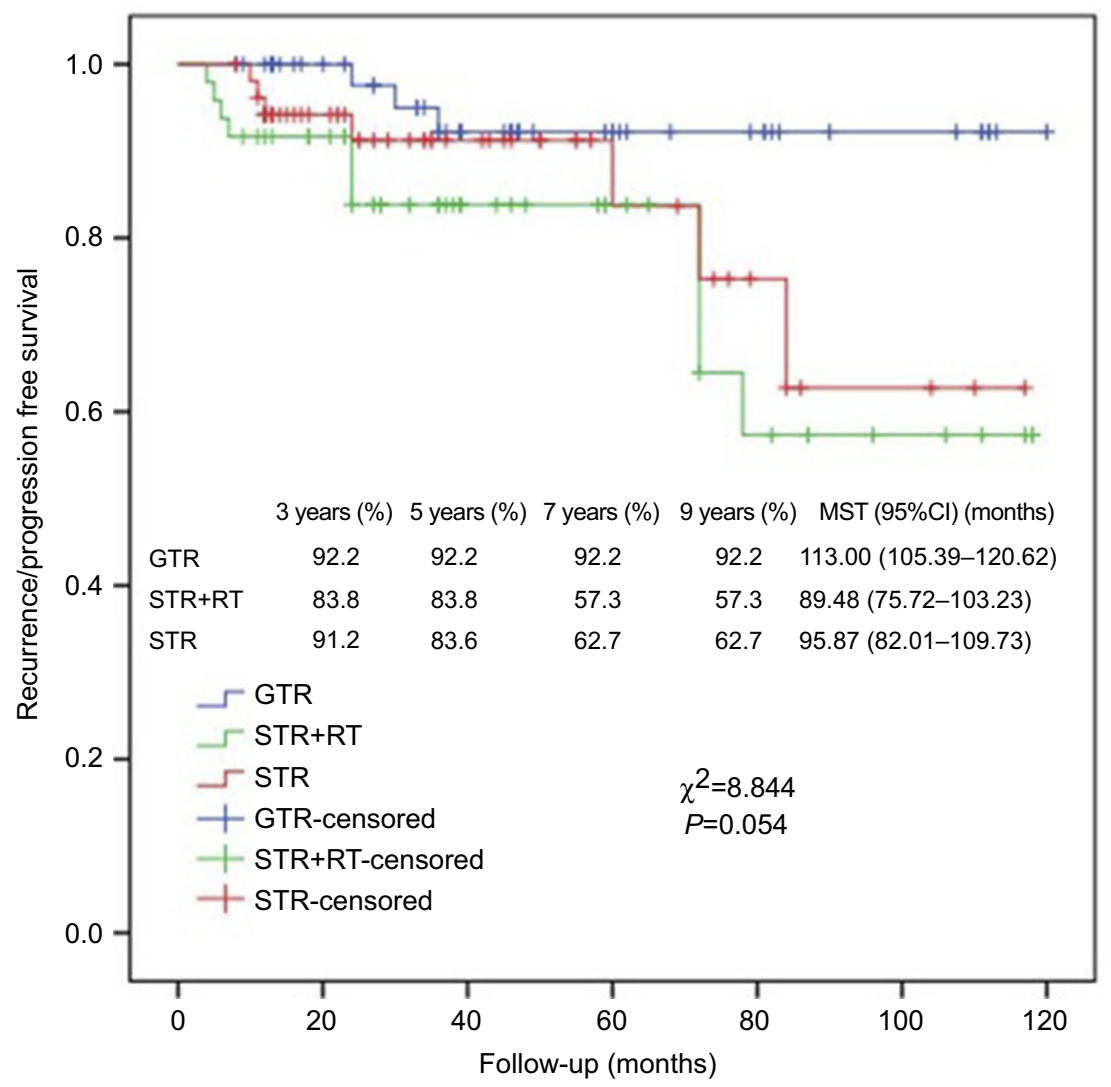

Figure 8 Kaplan-Meier analysis of R/P-free survival for resection modalities using log rank test.

Abbreviations: MST, mean survival time; GTR, gross total resection; STR, subtotal resection; RT, radiation therapy; R/P, recurrence/progression.

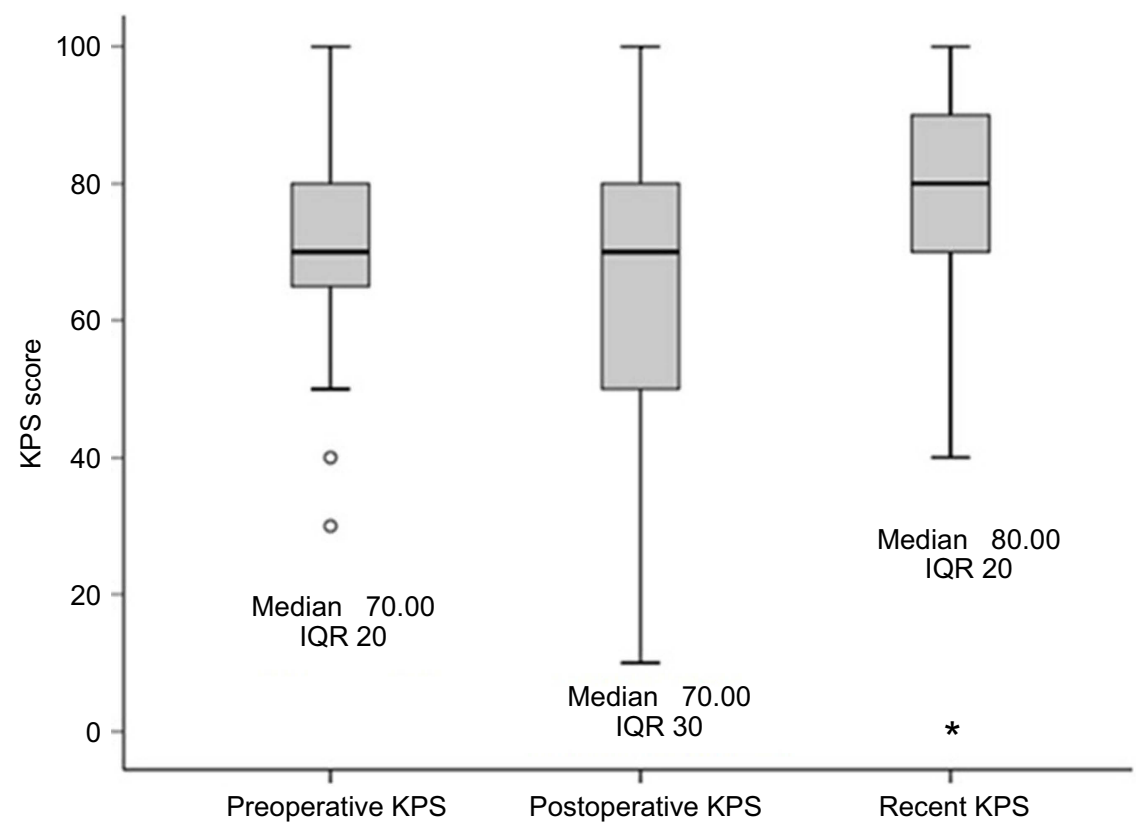

Figure 9 KPS scores of PCM patients receiving surgical resection.

Note: : outliers; ${ }^{*}$ : outlier.

Abbreviations: KPS, Karnofsky Performance Scale, PCM, petroclival meningioma. 
patients receiving STR without RT (125 months vs 66 months), and RT did not induce complications. This report indicated that GTR was difficult to perform in all patients without significant mortality and morbidity, and their data supported that RT was critical in delaying or preventing recurrence of meningiomas in subtotally resected tumors. Abdel Aziz et al further indicated that the optimal treatment for meningiomas was to resect the tumor as much as possible if safe, and meanwhile shape the residual tumor to an ideal radiosurgical target for adjuvant treatment. ${ }^{23}$ Therefore, in view of the reported data showing decreased yet still significant incidences of mortality and morbidity after GTR of PCMs, many researchers began to shift their treatment strategies away from aggressive resection to consideration of STR as an alternative.

Since 1998, GKS gradually gained significant popularity in managing PCMs, not only as an adjuvant therapy in STR lesions with sinus invasion or cranial nerve/vascular encasement but also as a primary treatment in symptomatic patients with small tumors. These results showed good tumor control and decreased mortality and morbidity. ${ }^{24-27}$ PFS at 5 and 10 years was better in benign skull base meningioma patients receiving GKS (98.5\% and $97.2 \%$, respectively) than in patients receiving microsurgical conventional RT, or LINAC-based radiosurgery. ${ }^{28}$ Another report showed that 10-year control rate of GKS was similar to that of resection in Simpson grade I benign meningiomas, which further confirmed efficacy and safety of stereotactic radiosurgery in newly found small symptomatic tumors. ${ }^{29}$ These reports also advocated a shift in surgical objective from radical resection to preservation of normal tissue as much as possible and preservation of function, with adjuvant GKS applied in treating the remaining tumor burden.

In this study, $72.2 \%$ of patients received only surgery, $8.5 \%$ received surgery + RT, and $19.3 \%$ received surgery + GKS. GTR was performed in $35.2 \%$ of patients, STR in $58.0 \%$ and PR in 7.4\%. Recent follow-up KPS was higher than preoperative and postoperative KPS. Cumulative survival was the same for $3,5,7$, and 9 years, ie, $95 \%$, and MST was (110.83 \pm 2.55 ) months (95\%CI: 105.83-115.83). $\mathrm{R} / \mathrm{P}$-free survival was $88.9 \%, 86.9 \%, 71.1 \%$ and $71.1 \%$, respectively for $3,5,7$, and 9 years, and MST was (100.58 \pm 3.82 ) months (95\%CI: 93.11-108.06). Therefore, surgical treatment was safe and effective. In addition, Cox regression analysis showed that R/P, surgery + RT and WHO grade III were independently associated with cumulative survival, and adhesion and encasement to neurovascular structures was independently associated with R/P-free survival. In this study, adjuvant RT was applied to WHO grade II/III meningiomas undergoing GTR and residual meningiomas after STR or PR which were prone to recur and progress. Adjuvant GKS was applied to residual meningiomas after STR or PR which were prone to recur and progress and patients who refused to RT due to poor physical condition. Surgery alone was applied to WHO grade I meningiomas undergoing GTR and patients who refused to RT due to poor physical condition. More patients preferred to GKS because of its convenience and effectiveness. There was no significant difference between patients receiving adjuvant RT and GKS in terms of age (mean 45 vs 46 years, $P=0.81$ ), KPS (mean 72 vs 74 , $P=0.59$ ), distribution of tumor grade (grade I 75 vs $80 \%$, grade II 19 vs $17 \%$, grade III 6 vs $3 \%, P=0.86$ ), and distribution of extent of resection (GTR 12 vs $8 \%$, STR 69 vs $78 \%$, PR 19 vs $14 \%, P=0.68)$. Thus, GKS was at least, to a certain extent, better than RT despite the limitation of nonrandomization. As a retrospective analysis, the main limitation of this study was that grouping of participants was not randomized.

\section{Conclusion}

Surgical treatment was safe and effective for PCM. R/P, surgery + RT and WHO grade III were independently associated with cumulative survival. Lack of adhesion to and encasement of neurovascular structures was independently associated with R/P-free survival. These factors should be paid attention to in surgical treatment of PCM.

\section{Author contributions}

All authors contributed towards data analysis, drafting and critically revising the paper, gave final approval of the version to be published, and agree to be accountable for all aspects of the work.

\section{Disclosure}

The authors report no financial or nonfinancial competing or conflicting interests in regard to this work.

\section{References}

1. Nanda A, Javalkar V, Banerjee AD. Petroclival meningiomas: study on outcomes, complications and recurrence rates. J Neurosurg. 2011;114 (5):1268-1277. doi:10.3171/2010.11.JNS10326

2. Li D, Hao SY, Wang L, et al. Surgical management and outcomes of petroclival meningiomas: a single-center case series of 259 patients. Acta Neurochir (Wien). 2013;155(8):1367-1383. doi:10.1007/s00701013-1795-9 
3. Pirayesh A, Petrakakis I, Raab P, et al. Petroclival meningiomas: magnetic resonance imaging factors predict tumor respectability and clinical outcome. Clin Neurol Neurosurg. 2016;147:90-97. doi:10.1016/j.clineuro.2016.06.002

4. Almefty R, Dunn IF, Pravdenkova S, Abolfotoh M, Al-Mefty O. True petroclival meningiomas: results of surgical management. J Neurosurg. 2014;120(1):40-51. doi:10.3171/2013.8.JNS13535

5. Natarajan SK, Sekhar LN, Schessel D, Morita A. Petroclival meningiomas: multimodality treatment and outcomes at long-term follow-up. Neurosurgery. 2007;60(6):965-979; discussion 979-981. doi:10.1227/01.NEU.0000255472.52882.D6

6. Bricolo AP, Turazzi S, Talacchi A, Cristofori L. Microsurgical removal of petroclival meningiomas: a report of 33 patients. Neurosurgery. 1992;31(5):813-828; discussion 828. doi:10.1227/ 00006123-199211000-00001

7. Castellano F, Ruggiero G. Meningiomas of the posterior fossa. Acta Radiol Suppl. 1953;104:1-177.

8. Couldwell WT, Fukushima T, Giannotta SL, Weiss MH. Petroclival meningiomas: surgical experience in 109 cases. J Neurosurg. 1996;84 (1):20-28. doi:10.3171/jns.1996.84.1.0020

9. Hakuba A, Nishimura S. Total removal of clivus meningiomas and the operative results. Neurol Med Chir (Tokyo). 1981;21(1):59-73.

10. Wayhs SY, Lepski GA, Frighetto L, Isolan GR. Petroclival meningiomas: remaining controversies in light of minimally invasive approaches. Clin Neurol Neurosurg. 2017;152:68-75. doi:10.1016/j. clineuro.2016.11.021

11. Maurer AJ, Safavi-Abbasi S, Cheema AA, Glenn CA, Sughrue ME. Management of petroclival meningiomas: a review of the development of current therapy. J Neurol Surg B Skull Base. 2014;75 (5):358-367. doi:10.1055/s-0034-1373657

12. Li D, Hao SY, Wang L, et al. Recurrent petroclival meningiomas: clinical characteristics, management, and outcomes. Neurosurg Rev. 2015;38(1):71-86; discussion 86-87. doi:10.1007/s10143-014-0575-1

13. Hunter JB, Weaver KD, Thompson RC, Wanna GB. Petroclival meningiomas. Otolaryngol Clin North Am. 2015;48(3):477-490. doi:10.1016/j.otc.2015.02.007

14. Diamandis P, Aldape K. World Health Organization 2016 classification of central nervous system tumors. Neurol Clin. 2018;36 (3):439-447. doi:10.1016/j.ncl.2018.04.003

15. Samii M, Ammirati M, Mahran A, Bini W, Sepehrnia A. Surgery of petroclival meningiomas: report of 24 cases. Neurosurgery. 1989;24 (1):12-17. doi:10.1227/00006123-198901000-00003

16. Mayberg MR, Symon L. Meningiomas of the clivus and apical petrous bone. Report of 35 cases. J Neurosurg. 1986;65 (2):160-167. doi:10.3171/jns.1986.65.2.0160
17. Sekhar LN, Wright DC, Richardson R, Monacci W. Petroclival and foramen magnum meningiomas: surgical approaches and pitfalls. J Neurooncol. 1996;29(3):249-259.

18. Simpson D. The recurrence of intracranial meningiomas after surgical treatment. J Neurol Neurosurg Psychiatry. 1957;20(1):22-39. doi:10.1136/jnnp.20.1.22

19. Haie-Meder C, Brunel P, Cioloca C, et al. Radiotherapy for treatment of meningioma and meningiosarcoma. Bull Cancer Radiother. 1995;82(1):35-39. French.

20. Yamashita J, Handa H, Iwaki K, et al. Recurrence of intracranial meningiomas, with special reference to radiotherapy. Surg Neurol. 1980;14(1):33-40.

21. Friedman M. Irradiation of meningioma: a prototype circumscribed tumor for planning high-dose irradiation of the brain. Int $J$ Radiat Oncol Biol Phys. 1977;2(9-10):949-958.

22. Barbaro NM, Gutin PH, Wilson CB, Sheline GE, Boldrey EB, Wara WM. Radiation therapy in the treatment of partially resected meningiomas. Neurosurgery. 1987;20(4):525-528. doi:10.1227/ 00006123-198704000-00003

23. Abdel Aziz KM, Sanan A, van Loveren HR, et al. Petroclival meningiomas: predictive parameters for transpetrosal approaches. Neurosurgery. 2000;47(1):139-150; discussion 150-152.

24. Subach BR, Lunsford LD, Kondziolka D, Maitz AH, Flickinger JC. Management of petroclival meningiomas by stereotactic radiosurgery. Neurosurgery. 1998;42(3):437-443; discussion 443-445. doi:10.1097/00006123-199803000-00001

25. Iwai Y, Yamanaka K, Yasui T, et al. Gamma knife surgery for skull base meningiomas. The effectiveness of low-dose treatment. Surg Neurol. 1999;52(1):40-44; discussion 44-45.

26. Roche PH, Pellet W, Fuentes S, Thomassin J-M, Régis J. Gamma knife radiosurgical management of petroclival meningiomas results and indications. Acta Neurochir (Wien). 2003;145(10):883-888; discussion 888. doi:10.1007/s00701-003-0123-1

27. Starke RM, Nguyen JH, Rainey J, et al. Gamma knife surgery of meningiomas located in the posterior fossa: factors predictive of outcome and remission. J Neurosurg. 2011;114(5):1399-1409. doi:10.3171/2010.11.JNS101193

28. Kreil W, Luggin J, Fuchs I, Weigl V, Eustacchio S, Papaefthymiou G. Long term experience of gamma knife radiosurgery for benign skull base meningiomas. J Neurol Neurosurg Psychiatry. 2005;76 (10):1425-1430. doi:10.1136/jnnp.2004.049213

29. Flannery TJ, Kano H, Lunsford LD, et al. Long-term control of petroclival meningiomas through radiosurgery. $J$ Neurosurg. 2010;112(5):957-964. doi:10.3171/2009.8.JNS09695
Cancer Management and Research

\section{Publish your work in this journal}

Cancer Management and Research is an international, peer-reviewed open access journal focusing on cancer research and the optimal use of preventative and integrated treatment interventions to achieve improved outcomes, enhanced survival and quality of life for the cancer patient.
The manuscript management system is completely online and includes a very quick and fair peer-review system, which is all easy to use. Visit http://www.dovepress.com/testimonials.php to read real quotes from published authors. 